\title{
The use of alpha particle tagged neutrons for the inspection of objects on the sea floor for the presence of explosives
}

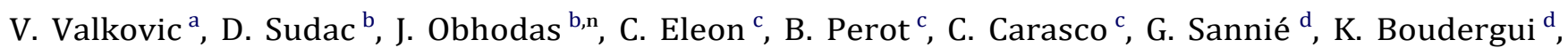 \\ V. Kondrasovs ${ }^{d}$, G. Corre ${ }^{d}$, S. Normand $^{d}$, R. Woo ${ }^{d}$, J.M. Bourbotte ${ }^{\mathrm{d}}$ \\ ${ }^{a}$ A.C.T.d.o.o. Analysis and Control Technologies, Prilesje 4, 10000 Zagreb, Croatia \\ ${ }^{\mathrm{b}}$ Ruder Boskovic Institute, Bijenicka c. 54, 10000 Zagreb, Croatia \\ ${ }^{\mathrm{c}}$ CEA, DEN, Cadarache, Nuclear Measurement Laboratory, F-13108 Saint-Paul-lez-Durance, France \\ ${ }^{\mathrm{d}}$ CEA, LIST, Saclay, F-91191 Gif-sur-Yvette, France
}

\begin{abstract}
A b s t r a c t
A system using a neutron sensor installed within a Remotely Operated Vehicle (ROV) for underwater inspection has been developed. The system can inspect objects for the presence of threat materials, such as explosives and chemical agents, by using alpha particle tagged neutrons from a sealed tube dpt neutron generator to produce characteristic gamma rays within the interrogated object.

Here we show that the measured gamma spectra for commonly found ammunition charged with TNT explosives are dominated by $\mathrm{C}$, $\mathrm{O}$ and Fe peaks enabling the underwater determination of explosives inside an ammunition shell.
\end{abstract}

\section{Introduction}

Since World War I, ammunition and chemical weapons have been often disposed of by dumping in the sea. The amount of dumped materials presents a challenging problem regarding the safety and security of coastal and underwater areas as well as ports and ships that has to be addressed and resolved by new specialized products and methods. The challenge of the research described here was to provide advanced tools for fast and robust non-destructive in-situ inspection of underwater objects in terms of chemical analysis. Besides chemical composition, this analysis can provide information on the size of the object, as well as about the volume of the analyzed substance contained by the object. This enables planning of the appropriate clearance actions, saving divers from the dangerous first contact with objects such as military explosives and chemical weapons. Commonly used military explosives are characterized by the presence of only four chemical elements, carbon (C), hydrogen $(\mathrm{H})$, nitrogen $(\mathrm{N})$ and oxygen $(\mathrm{O})$, inside an investigated object such as a mine, shell, or grenade made of iron (Fe) or aluminum (Al). The presence of phosphorus $(\mathrm{P})$, sulfur $(\mathrm{S})$, chlorine $(\mathrm{Cl})$, fluorine $(\mathrm{F})$, arsenic (As) and bromine (Br) in an iron barrel (identified by $\mathrm{Fe}$ ) or a glass jar (identified by $\mathrm{Si}$ ) can be related to the presence of $\mathrm{CW}$ agents [1\#. The ROV constructed under the EU FP7 UNCOSS project carries a $14 \mathrm{MeV}$ neutron sensor with the associated alpha particle

\footnotetext{
${ }^{\mathrm{n}}$ Corresponding author. Tel.: p385 14681 161; fax: p385 14680239
}

E-mail address: jobhodas@irb.hr (J. Obhodas). detection sensor and can be used for the inspection of objects lying on the sea floor containing a TNT surrogate. It was previously established that objects can be easily distinguished from the background [2]. The following parameters are of importance $[3,4]$ :

1. Distance of the object (i.e. explosive charge) from the neutron sensor due to the effect of fast neutron attenuation in sea water.

2. Thickness of the object's wall (neutron attenuation in the iron shell, mainly, sometimes aluminum).

3. Choice of the tagged neutron beam angle. This parameter can be satisfied either by

(i) rotation of the neutron generator, or by

(ii) use of a multisectorial alpha particle detector inside the neutron generator so that all angles are measured simultaneously.

4. Proper selection of the gamma ray detector.

5. Choice of the part of the object to be scanned for the explosive/threat material presence (this can introduce additional attenuation or complete miss of the explosive charge).

The three most important requirements for the ROV to function properly are

1. ROV stability during the measurement time ( $>10 \mathrm{~min}$ ) with- out touching the object. This was ensured by landing the ROV 
above the inspected object on four hydraulic legs whose length was remotely controlled [5].

2. Fine positioning of the ROV (cm-scale). This was performed by the use of 8 brushless thrusters.

3. The requirement that the position and size of the explosive charge (or other threat material) could be determined by neutron generator rotation.

\section{Data acquisition system performance}

The neutron-based sensor for explosive detection is composed of Russian made ING-27, a $14 \mathrm{MeV}$ neutron generator with $3 \times 3$ pixels associated alpha particle detector [6], a $30 \mathrm{~cm}$ detector shielding made of iron, a $3^{\prime} \times 3^{\prime} \mathrm{LaBr}_{3}(\mathrm{Ce})$ gamma detector [7] and the data acquisition electronics (DAQ), specifically developed for the UNCOSS project [8]. The tagged neutron beam is directed under a 451 angle with respect to the inspected object (see Fig. 1).

The neutron system is located inside the ROV which is made from a carbon fiber. The ROV also includes a titanium window in order to avoid the interaction between the tagged neutron beam and the carbon from the ROV hull, since carbon is a key element for explosive detection (see Section 4).

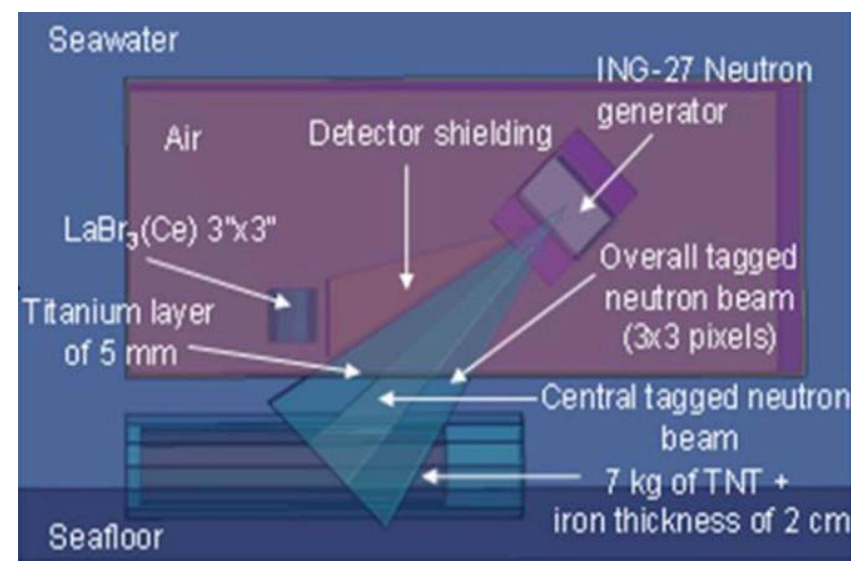

Fig. 1. Graphical presentation of the inspection setup.
The linearity of the neutron sensor was verified by recording the number of counts in the $4.439 \mathrm{MeV}$ carbon peak in a fixed graphite target as a function of neutron emission and by increasing the rate up to the maximum value of $5.8 \times 10^{7} \mathrm{n} / \mathrm{s}$ allowed by the ING-27 generator. In addition, it was verified that count losses were negligible by placing a fixed ${ }^{60} \mathrm{Co}$ source near the gamma detector and by recording the counts in the $1.33 \mathrm{MeV}$ peak as a function of the neutron emission. These preliminary tests demonstrated the good linearity and stability of the sensor. The overall time resolution of the DAQ system was 3 ns (FWHM). This allowed eliminating the contribution of the iron walls of the neutron generator (thickness of a few $\mathrm{mm}$ [6], see Fig. 2). The overall time resolution observed on the narrow peaks of Fig. 2 is a result of a DAQ resolution, alpha and gamma detector resolution (. $1.3 \mathrm{~ns}$ for the $\mathrm{LaBr}$ detector), and the iron wall thickness.

\section{Alpha pixel mapping and UXO positioning}

A large graphite target $\left(10 \times 50.5 \times 40 \mathrm{~cm}^{3}\right)$ was placed below the ROV to co-relate the relative efficiency of different tagged neutron beams associated to different alpha pixels of the neutron generator. Fig. 3 shows that pixels $\# 2$ and \#3 are the most effective ones; pixel \#2 just below the gamma detector logically showing the maximum signal.

In addition, it must be noted that some tagged beams are directed at regions which are partially shielded with respect to the gamma detector because of the ROV hull (for instance pixels $\# 1$, \#4 and \#7 are partially masked by the ROV hull).

In order to find the optimal position for real measurement conditions, the experiment was carried out with a carbon target $\left(10 \times 10 \times 10 \mathrm{~cm}^{3}\right)$ placed under the ROV and moved in the $X$ and $Y$ directions. Fig. 4 presents the carbon peak counts by the alpha pixels \#2 and \#5. It shows that the tagged neutron beam longitudinal axis (i.e. parallel to the longer axis of the titanium plate), which is at $X=0 \mathrm{~cm}$, is shifted to $X=-5 \mathrm{~cm}$.

The $5 \mathrm{~cm}$ shift is due to the fact that the tagged neutron beam axis is not exactly perpendicular to the alpha detector plane. The reason for this deviation is the residual kinetic energy of the deuterium ions colliding with the tritium target inside the neutron generator (see for instance Ref.[9]). Therefore, the optimal UXO (unexploded ordnance) positioning below the ROV is just below the gamma-ray detector $(Y=0)$ and on the neutron beam axis $(X=-5 \mathrm{~cm})$. The $5 \mathrm{~cm}$ shift has been corrected in the
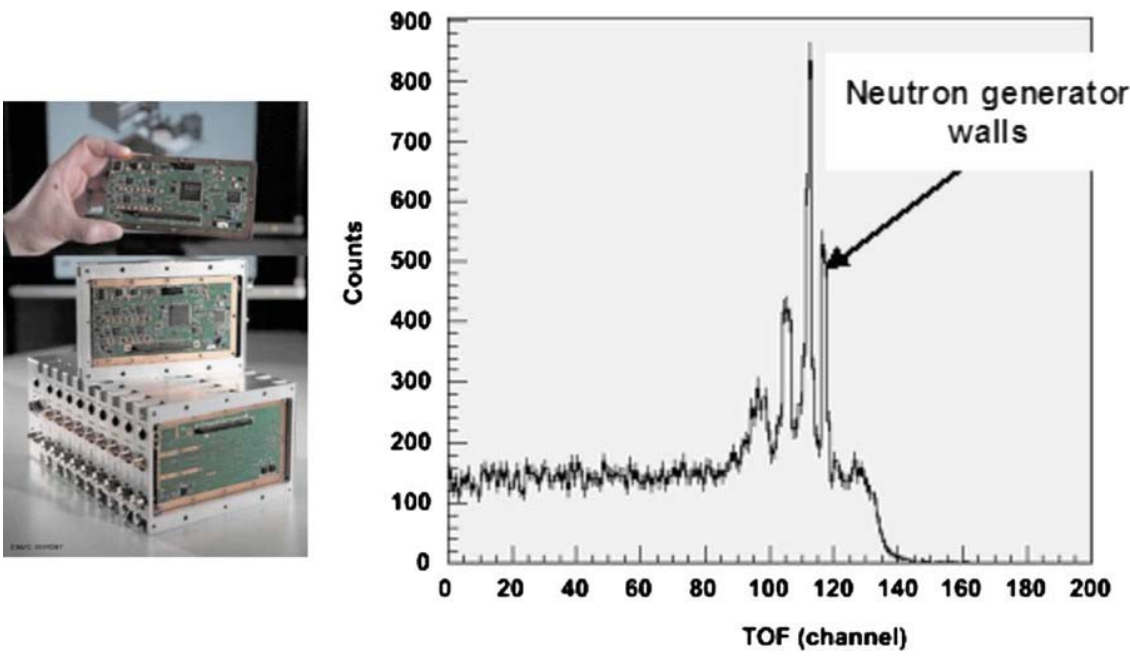

Fig. 2. Newly developed DAQ (on the left) and time-of-flight (TOF) spectrum showing narrow peaks associated to the few mm thick iron walls of the neutron generator (on the right). 

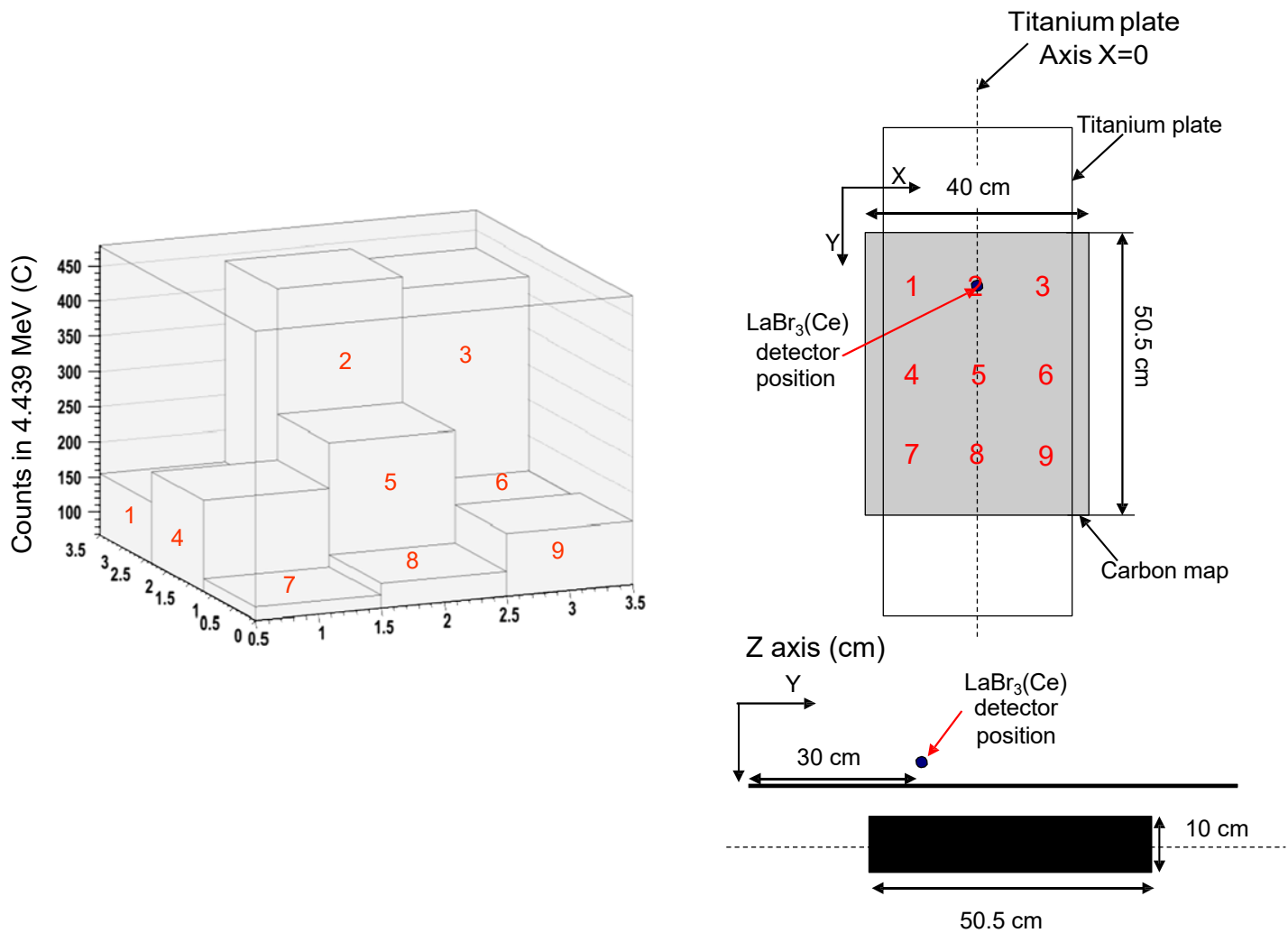

Fig. 3. Alpha pixel map (left) corresponding to the counts in the $4.439 \mathrm{MeV}$ carbon peak induced by the different tagged neutron beams from the plan graphite target located $5 \mathrm{~cm}$ below the ROV titanium window (right).

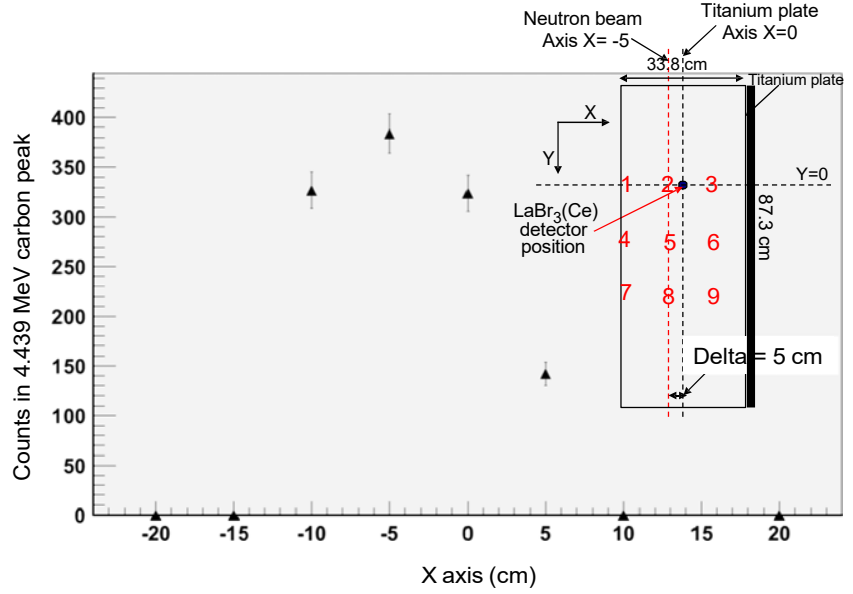

Fig. 4. Number of counts in the $4.439 \mathrm{MeV}$ carbon peak according to $X$-axis position of the $10 \times 10 \times 10 \mathrm{~cm}^{3}$ graphite cube.

final setup by slightly rotating the neutron generator inside the ROV, thus also improving the signal of pixels $\# 1, \# 4$ and $\# 7$, which were partially masked by the ROV hull. The width of the projection of the tagged beam associated to the optimal pixel $\# 2$, on an inspected object located $5 \mathrm{~cm}$ below the ROV, is approximately $15 \mathrm{~cm}(\mathrm{FWHM})$.

\section{Experimental assessment for underwater inspection}

The preliminary underwater performance assessment tests were carried out in the Punat seaport on the island of Krk, Croatia. The inspected objects were attached parallel to the ROV and the measurements were performed with the ROV/object direct contact to ascertain their relative positioning with respect to the tagged beam as well as to minimize the thickness of the seawater layer. This reduced the oxygen contribution to the measured spectra, thus increasing sensitivity. As a result of the previous alpha pixel mapping presented in Fig. 3 , central pixels $\# 2, \# 5$ and $\# 8$ were selected for data acquisition. The measurements were carried out with two identical cylinders, $16 \mathrm{~cm}$ diameter and $12 \mathrm{~mm}$ thick, filled with $\sim 11 \mathrm{~kg}$ of local sediments from the Punat test site and with $\sim 13 \mathrm{~kg}$ of TNT surrogate with the composition $\mathrm{C}_{7} \mathrm{H}_{6} \mathrm{~N}_{3} \mathrm{O}_{6}$. Additional tests were performed with an airplane bomb (diameter of $20 \mathrm{~cm}$ and iron thickness of $2 \mathrm{~mm}$ ) filled with $\sim 30 \mathrm{~kg}$ of another TNT surrogate with the composition $\mathrm{Si}_{3} \mathrm{C}_{7} \mathrm{H}_{3} \mathrm{~N}_{3} \mathrm{O}_{6}$ and with a $120 \mathrm{~mm}$ grenade filled with $\sim 3 \mathrm{~kg}$ of the $\mathrm{C}_{7} \mathrm{H}_{6} \mathrm{~N}_{3} \mathrm{O}_{6}$ TNT surrogate. The TNT surrogate has been selected for the experiments since TNT is the most common explosive found in ammunition present on the sea floor $[3,4]$

Fig. 5 shows the time and energy spectra for the $16 \mathrm{~cm}$ diameter and $12 \mathrm{~mm}$ thick iron cylinder filled with TNT surrogate after $10 \mathrm{~min}$ acquisition time. The main characteristic peaks of iron (UXO shell), titanium (ROV window), carbon and oxygen (TNT surrogate) can be observed. With respect to laboratory measurements of the sensor stability (see Section 2), underwater inspections were performed with a neutron emission rate of $2.6 \times 10^{7} \mathrm{n} \mathrm{s}^{-1}$ instead of the maximum $5.8 \times 10^{7} \mathrm{n} \mathrm{s}^{-1}$. Indeed, neutron interactions with the surrounding environment strongly increase the gamma detector count rate and the associated random background, the last rinsing with the square of neutron emission.

The relative proportions of carbon, oxygen and nitrogen are commonly used for explosive detection (see Refs.[10,11] and references therein). However in underwater inspection of thick iron shells the characteristic peaks of nitrogen (mainly at $1.632 \mathrm{MeV}, 2.313 \mathrm{MeV}$ and $5.106 \mathrm{MeV}$ ) are strongly attenuated and in addition they are interfered by other lines such as the 2 nd escape of the $6.130 \mathrm{MeV}$ 

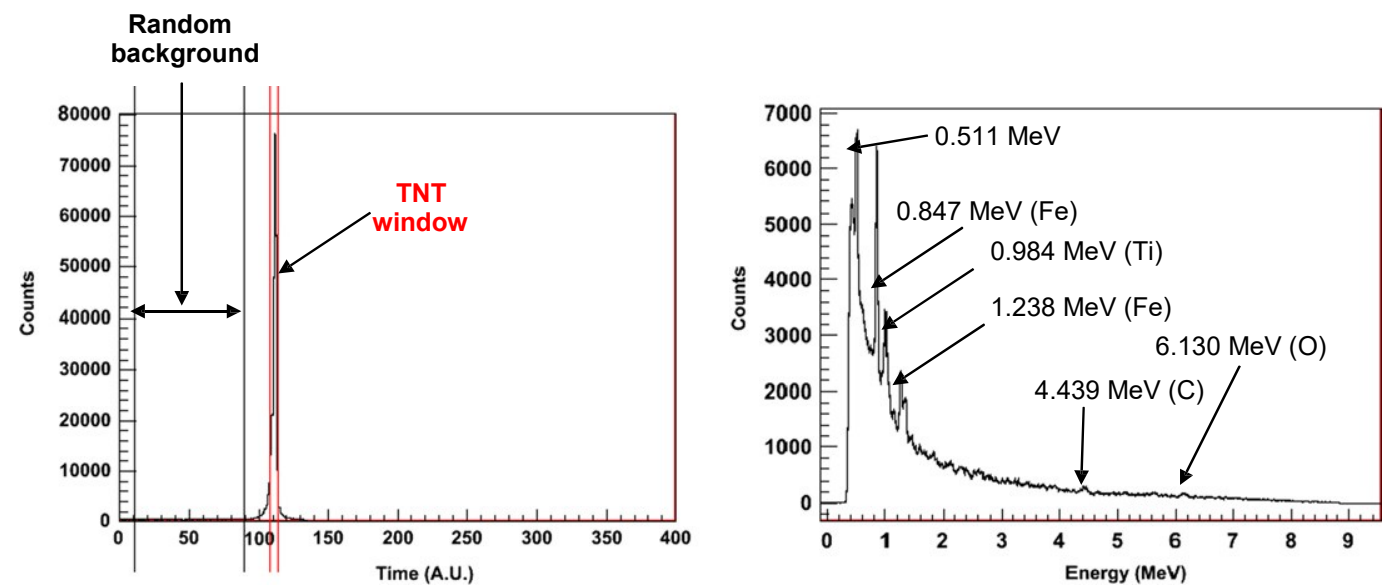

Fig. 5. TOF of the $16 \mathrm{~cm}$ diameter and $12 \mathrm{~mm}$ thick iron cylinder filled with TNT surrogate $\left(\mathrm{C}_{7} \mathrm{H}_{6} \mathrm{~N}_{3} \mathrm{O}_{6}\right.$; on the left) and energy spectra (on the right) measured in sea water for $10 \mathrm{~min}$ by the ROV. Average neutron emission was $2.6 \times 10^{7} \mathrm{n} \mathrm{s}^{-1}$.
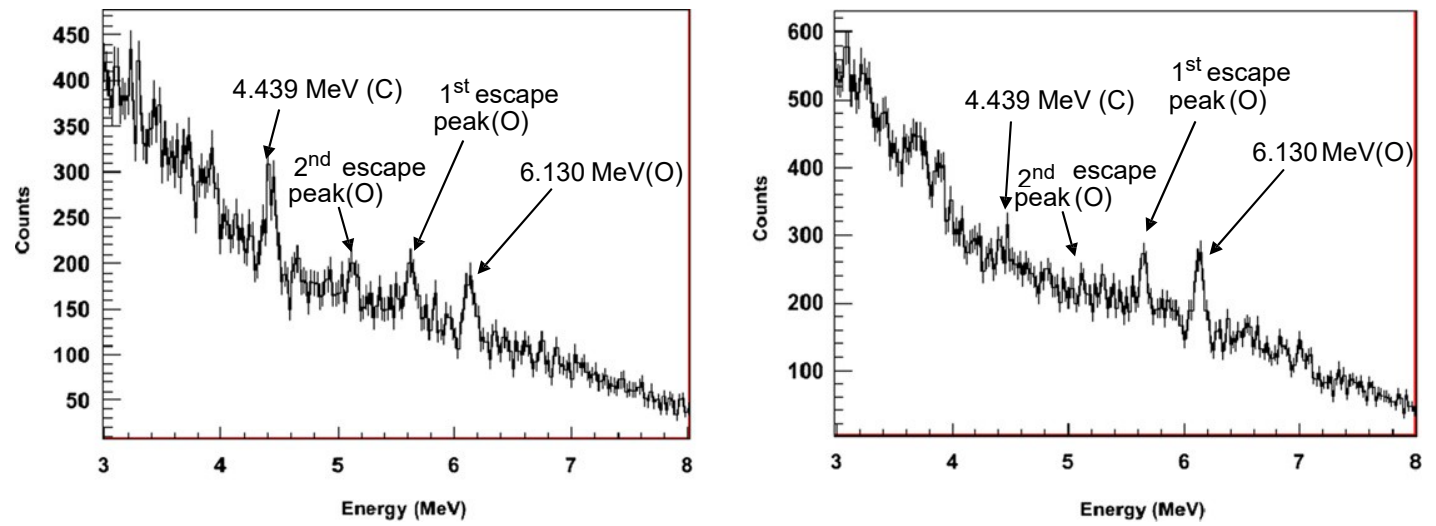

Fig. 6. Energy spectra of the $16 \mathrm{~cm}$ diameter and $12 \mathrm{~mm}$ thick iron cylinders measured for $10 \mathrm{~min}$ in sea water with an average neutron emission of $2.6 \mathrm{x} 10^{7} \mathrm{n} \mathrm{s}{ }^{-1}$ and by selecting the central alpha pixels \#2, \#5 and \#8: the cylinder filled with $\sim 13 \mathrm{~kg}$ of TNT surrogate (on the left) and an identical cylinder filled with local sand (on the right)

Table 1

Net peak area of $\mathrm{C}, \mathrm{O}$ and $\mathrm{C} / \mathrm{O}$ ratios measured in sea water by selecting the central alpha pixels \#2, \#5 and \#8 for the $20 \mathrm{~cm}$ airplane bomb and the $12 \mathrm{~cm}$ grenade, both filled with TNT surrogates, and for two identical $16 \mathrm{~cm}$ iron shells filled with TNT surrogate and with local sand. Three repeatability tests are reported for the cylinders, and for the grenade $10 \mathrm{~min}$ and 20 min acquisitions were performed.

\begin{tabular}{|c|c|c|c|}
\hline Measurements & $\begin{array}{l}\mathrm{C}(4.439 \mathrm{MeV} \\
\text { peak counts) }\end{array}$ & $\begin{array}{l}\mathrm{O}(6.130 \mathrm{MeV} \\
\text { peak counts })\end{array}$ & $\mathrm{C} / \mathrm{O}$ ratios \\
\hline $\begin{array}{l}\text { Iron cylinder filled with TNT } \\
\text { surrogate }(10 \mathrm{~min}) \text { Run No.1 }\end{array}$ & 252756 & 167752 & 1.5170 .58 \\
\hline $\begin{array}{l}\text { Iron cylinder filled with local } \\
\text { sand (10 min) Run No.1 }\end{array}$ & 90782 & 406766 & 0.2270 .21 \\
\hline $\begin{array}{l}\text { Iron cylinder filled with TNT } \\
\text { surrogate }(10 \mathrm{~min}) \text { run No.2 }\end{array}$ & 539776 & 365763 & 1.4870 .33 \\
\hline $\begin{array}{l}\text { Iron cylinder filled with local } \\
\text { sand ( } 10 \text { min) Run No.2 }\end{array}$ & 118781 & 556760 & 0.2170 .15 \\
\hline $\begin{array}{l}\text { Iron cylinder filled with TNT } \\
\text { surrogate }(10 \mathrm{~min}) \text { Run No.3 }\end{array}$ & 354765 & 259746 & 1.3770 .35 \\
\hline $\begin{array}{l}\text { Iron cylinder filled with local } \\
\text { sand (10 min) run No.3 }\end{array}$ & 234793 & 521766 & 0.4570 .19 \\
\hline Airplane bomb (10 min) & 615766 & 433745 & 1.4270 .21 \\
\hline Grenade $(10 \mathrm{~min})$ & 341795 & 355753 & 0.9670 .30 \\
\hline Grenade $(20 \mathrm{~min})$ & 11587148 & 7477104 & 1.5570 .29 \\
\hline
\end{tabular}

gamma ray of oxygen, at $5.108 \mathrm{MeV}$, or the $1.555 \mathrm{MeV}$ and 2.375 MeV peaks of titanium [12]. Therefore, for this application we performed a simpler but much more robust data analysis based on the carbon $4.439 \mathrm{MeV}$ and oxygen $6.130 \mathrm{MeV}$ net areas, the $\mathrm{C} / \mathrm{O}$

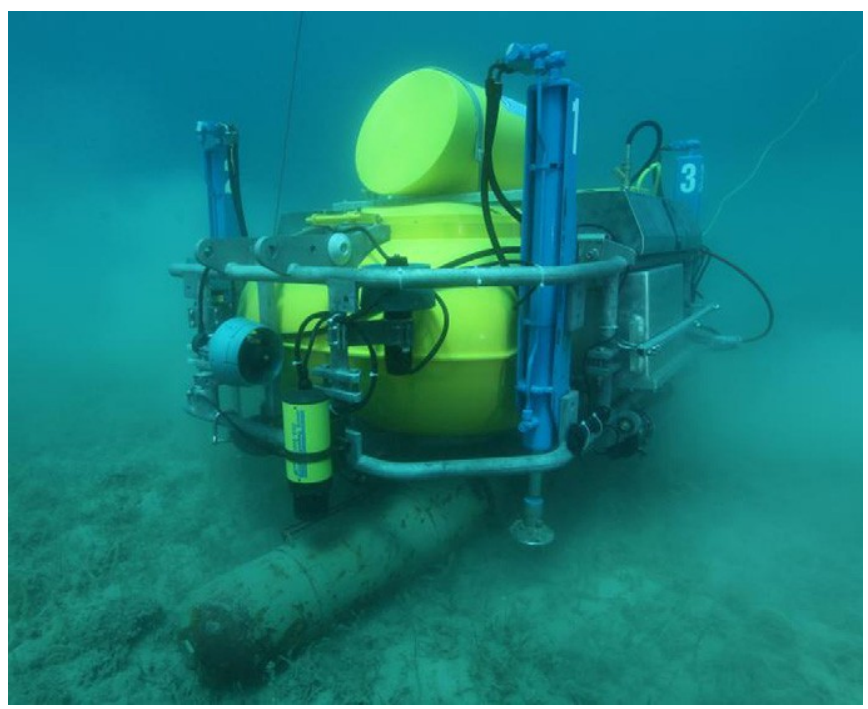

Fig. 7. Underwater inspection of the $20 \mathrm{~cm}$ diameter airplane bomb at the depth of $10 \mathrm{~m}$.

surface ratio being used to discriminate between metallic objects containing sediments or explosives. Fig. 6 and Table 1 show that the $\mathrm{C} / \mathrm{O}$ ratio allows the differentiation of a TNT surrogate from a sea sediment inside a thick iron shell. 

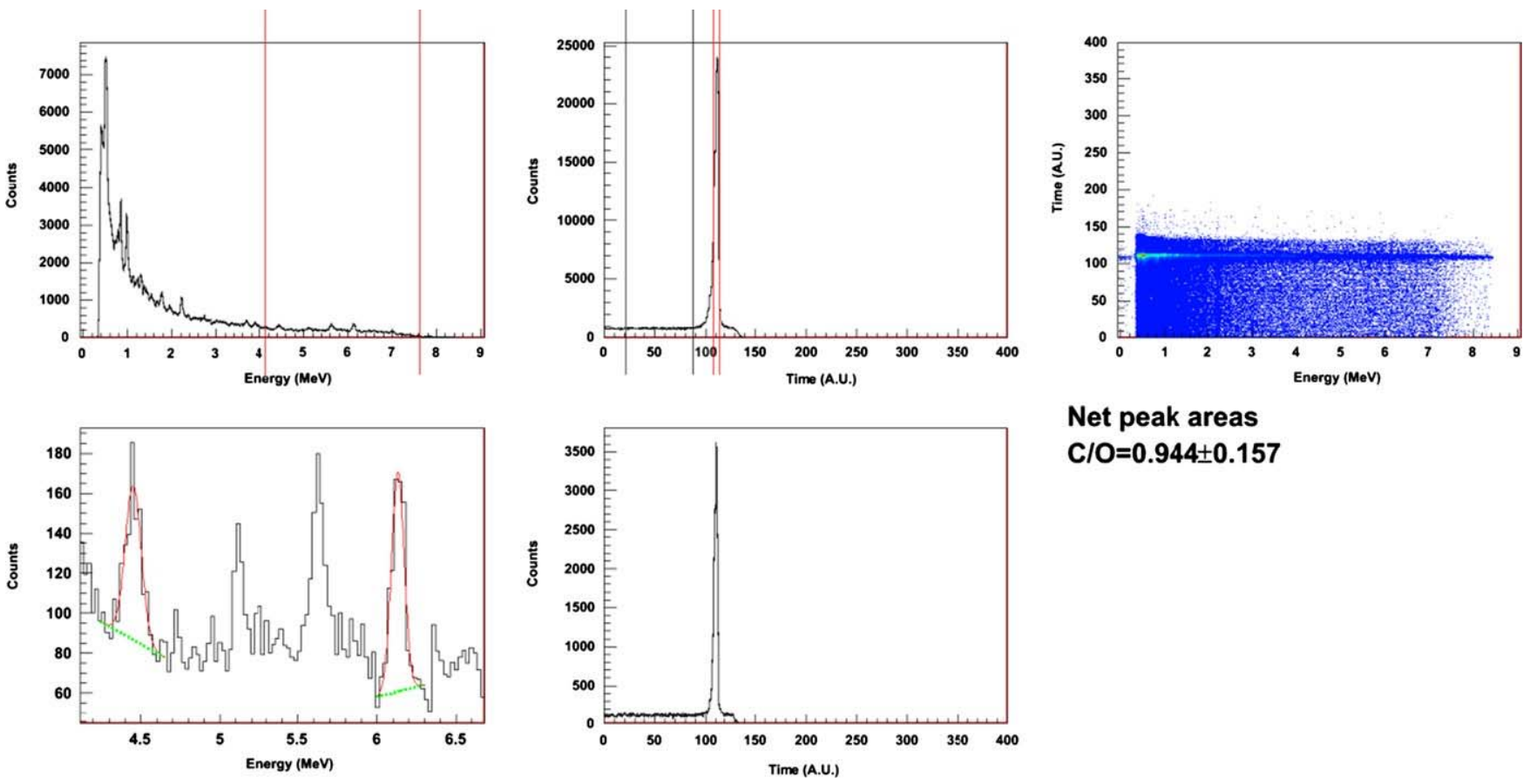

\section{Net peak areas \\ $\mathrm{C} / \mathrm{O}=0.944 \pm 0.157$}

Fig. 8. Panels of the data analysis software corresponding to a 10 min measurement of the airplane bomb filled with $\mathrm{TNT}_{\mathrm{N}}$ surrogate $\left(\mathrm{Si}_{3} \mathrm{C}_{7} \mathrm{H}_{3} \mathrm{~N}_{3} \mathrm{O}_{6}\right)$ in the seawater, with an average neutron emission of $3 \times 10^{7} \mathrm{n} \mathrm{s}^{-1}$ and by selecting alpha pixels \#3, \#6 and \#9.

\section{Field demonstration}

The final demonstration tests were also performed in Punat, Croatia, on a specific location with a depth of $10 \mathrm{~m}$. The ROV landed above the airplane bomb filled with the $\mathrm{Si}_{3} \mathrm{C}_{7} \mathrm{H}_{3} \mathrm{~N}_{3} \mathrm{O}_{6} \mathrm{TNT}$ surrogate without contact and the hydraulic legs allowed positioning the neutron sensor very close to the inspected object, see Fig. 7.

In comparison to Table 1 reported above, Fig. 8 shows that the $\mathrm{C} / \mathrm{O}$ ratio confirms the presence of TNT surrogate: $\mathrm{C} / \mathrm{O} 1 / 4$ 0.94470 .157 .

This value is a bit lower than the one reported in Section 4 for the airplane bomb because of the larger contribution of seawater oxygen in the energy spectrum due to a water layer between the ROV and the inspected object. Since the ROV and bomb axes were slightly shifted, pixels $\# 3, \# 6$ and $\# 9$ were used instead of pixels $\# 2$, \#5 and \#8 in previous measurements (see pixel map in Fig. 3).

The proposed procedure in future system measurements is to perform a calibration with different types of sediments in order to determine the sediment vs. explosives discrimination threshold. For instance, in the case of the Punat sand, data reported in Table 1 show that this threshold was around $\mathrm{C} / \mathrm{O} \sim 0.5$.

\section{Conclusion}

It has been shown that a neutron sensor with the flux of tagged $14 \mathrm{MeV}$ neutrons onboard a dedicated ROV can be used for the inspection of objects on the sea floor loaded with TNT surrogate in a $10 \mathrm{~min}$ data acquisition period. Gamma rays resulting from irradiating elements present in the explosive (carbon, oxygen) within an investigated object (iron) were used for the confirmation of explosive surrogate presence with a very good spatial resolution (mm-scale). The other sensors (magnetometer, cameras, etc.) enabled precise ROV positioning ( $\mathrm{cm}$-scale) above the inspected object without touching it.
Acknowledgment

This work is supported by the European Union within the 7th Framework Program, UNCOSS Project, Grant agreement No. 218148, http://www.uncoss-project.org.

References

[1] J. Obhodas, V. Valkovic, D. Sudac, D. Matika, I. Pavic, R. Kollar., Nuclear Instruments and Methods in Physics Research Section A 619 (2010) 419.

[2] J. Obhodas, D. Sudac, V. Valkovic., IEEE Transactions on Nuclear Science NS57 (5) (2010) 2762.

[3] V. Valkovic, D. Sudac, D. Matika, R. Kollar, Optics and Photonics in Global Homeland Security III 2007, in: T.T. Saito, D. Lehrfeld, M.J. DeWeert (Eds.), Proceedings of SPIE, International Society for Optics and Photonics, Bellingham, WA, USA, http://dx.doi.org/10.1117/12.718973, Orlando, FL, USA, 26 April 2007.

[4] D. Sudac, D. Matika, V. Valkovic, in: F.D. McDaniel, B.L. Doyle (Eds.), Proceedings of the 20th International Conference on Application of Accelerators in Research and Industry, vol.1099, American Institute of Physics, 2009, pp. 574-577, http://dx.doi.org/10.1063/1.3120102, Fort Worth, TX, 10-15 August 2008.

[5] V. Valkovic, D. Sudac, R. Kollar, Z. Domitran, K. Nad, J. Obhodas, in: J. T. Broach, J. H. Holloway Jr. (Eds.), Detection and Sensing of Mines, Explosive Objects, and Obscured Targets XVII 2012: Proceedings of SPIE, vol. 8357, Baltimore, MD, USA, 8 June 2012, International Society for Optics and Photonics, Bellingham, Washington, USA (2012), doi:10.1117/12.918125.

[6] All - Russian Research Institute of Automatics, VNIIA, Neutron Generator ING27 Operating Manual, ING-27 OM, see also commercial data sheet on /http:// www.vniia.ru/eng/ng/docs/ing_27eng.pdfs.

[7] C. Eleon, B. Perot, C. Carasco, Nuclear Instruments and Methods in Physics Research Section A 619 (2010) 234.

[8] C. Carasco, C. Eleon, B. Perot, K. Boudergui, V. Kondrasovs, G. Corre, S. Normand, G. Sannie, R. Woo, J.-M. Bourbotte, IEEE Transactions on Nuclear Science NS59 (4) (2012) 1438.

[9] S. Pesente, M. Lunardon, G. Nebbia, G. Viesti, D. Sudac, V. Valkovic, Applied Radiation and Isotopes 65 (2007) 1322

[10] C. Eleon, B. Perot, C. Carasco, D. Sudac, J. Obhodas, M. Baricevic, V. Valkovic, Nuclear Instruments and Methods in Physics Research Section A 629 (2011) 220.

[11] W. El Kanawati, B. Perot, C. Carasco, C. Eleon, V. Valkovic, D. Sudac, J. Obhodas, Nuclear Instruments and Methods in Physics Research Section A 654 (2011) 621.

[12] S.P. Simakov, A. Pavlik, H. Vonach, S. Hlavac, IAEA Nuclear Data Section, INDC(CCP)-413, 1998, available from /http://www-nds.iaea.org.reportsnew/indc-reports/indc-ccp/SS. 